\title{
Routine diagnosis of large granular lymphocytic leukaemia by Southern blot and polymerase chain reaction analysis of clonal $\mathrm{T}$ cell receptor gene rearrangements
}

\author{
D K Ryan, H D Alexander, T C M Morris
}

\begin{abstract}
Aims-To compare the polymerase chain reaction (PCR) assay with standard Southern blot (SB) hybridisation for the detection of clonal $T$ cell receptor (TCR) gene rearrangements in large granular lymphocyte (LGL) proliferations; to evaluate the reliability and practicality of the methods for routine diagnostic use; and to determine the sensitivity of the PCR method.
\end{abstract}

Methods-Blood lymphocytes were isolated from 12 patients with persistent $\mathrm{CD3}^{+} \mathrm{CD8}^{+}$lymphocytosis with LGL morphology. Clonal rearrangements of the TCR gene were demonstrated by SB hybridisation with a TCRß constant probe, and by PCR amplification of portions of the TCR $\beta$ and TCR $\gamma$ genes. Results-Monoclonal TCR $\beta$ gene rearrangements were detected in eight patients $(67 \%)$ by PCR analysis and five patients $(42 \%)$ by SB hybridisation. PCR analysis also showed that seven patients $(58 \%)$ had monoclonal TCR $\gamma$ gene rearrangements. All cases which had TCRB clonal rearrangements shown by SB hybridisation were similarly identified by PCR. Sensitivity tests suggested that the TCRß PCR technique was capable of detecting clonality in as little as $50 \mathrm{pg}$ of DNA. The TCR $\beta$ primers could detect one clonal cell in approximately 200 or more normal cells $(<0.5 \%)$, a sensitivity level that at least doubles that of the SB hybridisation technique.

Department of Haematology, Belfast City Hospital, Lisburn Road, Belfast BT9 7AB D K Ryan

H D Alexander

T C M Morris

Correspondence to: Dr Alexander.

Accepted for publication 7 January 1997
Conclusions-The use of PCR technology proved to be superior to SB hybridisation for the routine investigation of suspected cases of LGL leukaemia. Nine patients $(75 \%)$ in this study were found to have TCRß and/or TCR $\gamma$ monoclonal gene rearrangements. This approach is ideal for distinguishing between reactive and clonal LGL proliferation in a routine diagnostic laboratory.

( Clin Pathol: Mol Pathol 1997;50:77-81)
Keywords: Polymerase chain reaction; Southern blot hybridisation; $T$ cell receptor gene rearrangements; large granular lymphocytes; $T$ cell large granular lymphocytic leukaemia

T cell large granular lymphocytic leukaemia is a distinct disorder which results from a chronic proliferation of large granular lymphocytes (LGL) that are CD3 positive and express the $\mathrm{T}$ cell receptor complex. ${ }^{1}$ Clinical features may include a history of recurrent bacterial infections because of severe neutropenia as well as rheumatoid arthritis. ${ }^{2}$ The diagnosis of $\mathrm{T}$ cell LGL leukaemia has been restricted by the inability to distinguish reactive populations of T lymphocytes from neoplastic proliferations. ${ }^{13}$ Many persistent LGL expansions are clinically non-progressive and despite the common onset of neutropenia most patients only have a modest lymphocytosis even with the considerable increases in the absolute numbers of circulating LGLs. There is a lack of characteristic morphological and immunophenotypic features to distinguish clonal LGLs from their normal counterparts. In addition, there is a lack of suitable markers to confirm clonality and malignancy. The finding of clonal cytogenetic abnormalities in unstimulated cultures of peripheral blood and splenic mononuclear cells from some patients with LGL leukaemia provided the first evidence that this disease was of clonal origin. ${ }^{4}$ More recently, clonality has been demonstrated by molecular analysis of the TCR $\beta$, TCR $\gamma$, and TCR $\delta$ gene rearrangements. ${ }^{5-7}$ Rearranged TCR genes of lymphoid cells involving the combination of specific variable $(\mathrm{V})$, joining $(\mathrm{J})$, constant $(\mathrm{C})$, and in some cases diversity (D) gene segments are known to serve as unique clonal markers of lymphoid neoplasms. ${ }^{8}$ Several groups have used Southern blot (SB) hybridisation techniques for the clonal detection of LGL leukaemia. ${ }^{23579-11}$ More recently, polymerase chain reaction (PCR) analysis has been used to detect clonal $\mathrm{T}$ cell proliferations in patients with lymphoid disorders. ${ }^{12-14}$ The present study compared PCR with SB analysis for the routine detection of clonal TCR $\beta$ gene rearrangements 
Table 1 Primer sequences, combination, and expected size range of PCR products

\begin{tabular}{llll}
\hline Primer & Sequence $5^{\prime} \rightarrow 3^{\prime}$ & Primer combination & $\begin{array}{l}\text { Approximate size range } \\
\text { (base pairs) }\end{array}$ \\
\hline V $\beta$ & TGT A(C/T)C TCT GTG CCA GCA G & $\mathrm{V} \beta / \mathrm{J} \beta 1 ; \mathrm{V} \beta / \mathrm{J} \beta 2$ & $55-100$ \\
D $\beta 1$ & CAA AGC TGT AAC ATT GTG GGG AC & $\mathrm{D} \beta 1 / \mathrm{J} \beta 2$ & $55-100$ \\
D $\beta 2$ & TCA TGG TGT AAC ATT GTG GGG AC & $\mathrm{D} \beta 2 / \mathrm{J} \beta 2$ & $55-100$ \\
$\mathrm{~J} \beta 1$ & ACA GTG AGC C(G/T)G GT(T/C) CC & $\mathrm{D} \beta 2 / \mathrm{J} \beta 2$ & $55-100$ \\
$\mathrm{~J} \beta 2$ & AGC AC(C/T/G) GTG AGC C(T/G)G GTG CCC & $\mathrm{D} \beta 2 / \mathrm{J} \beta 2$ & $55-100$ \\
V $\gamma 11$ & TCT GG(G/A) GTC TAT TAC TGT GC & $\mathrm{V} \gamma 11 / \mathrm{V} \gamma 101 / \mathrm{J} \gamma 12$ & $70-110$ \\
V $\gamma 101$ & CTC ACA CTC (C/T)CA CTT C & $\mathrm{V} \gamma 11 / \mathrm{V} \gamma 101 / \mathrm{J} \gamma 12$ & $70-110$ \\
$\mathrm{~J} \gamma 12$ & CAA GTG TTG TTC CAC TGC C & $\mathrm{V} \gamma 11 / \mathrm{V} \gamma 101 / \mathrm{J} \gamma 12$ & $70-110$ \\
\hline
\end{tabular}

Primer sequences after McCarthy et al. ${ }^{12} 13$

in 12 patients with persistent proliferation of LGLs. The sensitivity of the PCR method was assessed by measuring the percentage of clonal cells. DNA used to detect the sensitivity of the PCR technique was taken from a patient known to have TCR $\beta$ monoclonal gene rearrangements (MGRs). It consisted of clonal DNA with a lower percentage of non-clonal DNA. This particular feature caused difficulty in interpreting a precise clonal detection limit due to the dilution factor caused by the non-clonal DNA. Thus, an approximate evaluation of PCR sensitivity using TCR $\beta$ primers was made. Clonal TCR $\gamma$ gene rearrangements were also investigated by PCR and evaluated for routine diagnostic use.

\section{Patients and methods}

Twelve patients with persistently increased numbers of $\mathrm{CD}^{+} \mathrm{CD}^{+} \mathrm{T}$ cells with LGL morphology were studied. Patients variously had a history of recurrent infection, arthritis, and neutropenia, features typical of LGL leukaemia. ${ }^{12}$ Peripheral blood mononuclear cells were separated from heparinised blood by Ficoll Paque (Pharmacia, Uppsala, Sweden) sedimentation, washed in Hank's balanced salt solution (HBSS), pelleted, and stored at $-80^{\circ} \mathrm{C}$ until used for DNA analysis. High molecular weight DNA was obtained by cell lysis, deproteinisation, chloroform extraction, and ethanol precipitation as described previously. ${ }^{15}$

\section{CONTROLS}

Peripheral blood samples known to be positive for TCR $\beta$ and/or TCR $\gamma$ clonal gene rearrangements were chosen as positive controls. Two normal peripheral blood samples were used as negative controls. Both positive and negative peripheral blood samples were prepared and tested similarly to the patient samples. During PCR analysis, an extra negative control consisting solely of PCR mix without the addition of DNA template was used to detect any possible signs of contamination.

SOUTHERN BLOT HYBRIDISATION

For SB analysis, DNA was digested with three restriction enzymes EcoRI, BamHI and HindIII. The digested DNA was size fractionated by agarose gel electrophoresis followed by denaturation, neutralisation, and transfer to a nylon membrane (Hybond $\mathrm{H}^{+}$, Amersham Life Science, Amersham) by Southern blotting. ${ }^{15}{ }^{16} \mathrm{~A}$ ${ }^{32} \mathrm{P}$ radiolabelled genomic probe homologous to the $C$ region of the TCR $\beta$ gene was hybrid- ised with the DNA fragments. The nylon membrane was washed twice for 15 minutes in $150 \mathrm{mM}$ sodium chloride, $20 \mathrm{mM}$ sodium citrate, and $0.2 \%$ sodium dodecyl sulphate (SDS) at $65^{\circ} \mathrm{C}$. Two final washes using a higher stringency wash of $15 \mathrm{mM}$ sodium chloride, $2 \mathrm{mM}$ sodium citrate, and $0.2 \%$ SDS were performed for 15 minutes each at $65^{\circ} \mathrm{C}$. Autoradiographic exposure was carried out at $-80^{\circ} \mathrm{C}$ for 24 to 96 hours.

\section{PCR CONDITIONS}

The PCR protocol was essentially performed as described by McCarthy et al using primers specific for the detection of complete and partial TCR $\beta$ MGRs, and complete TCR $\gamma$ monoclonal rearrangements (table 1). ${ }^{12}{ }^{13} \mathrm{~A}$ master mix was prepared on ice so that each $25 \mu \mathrm{lPCR}$ reaction contained $1 \times$ Taq buffer, $200 \mu \mathrm{M}$ nucleotides, $1.5 \mathrm{mM}$ magnesium chloride, 68 pmol of each primer, and 0.125 units of Taq polymerase. DNA template $(0.25 \mu \mathrm{g})$ was added to $25 \mu \mathrm{l}$ of PCR mix in a $0.5 \mathrm{ml}$ microtube and covered with a drop of light mineral oil (Perkin Elmer Ltd, Warrington). The microtubes were incubated in a thermocycler (DNA Thermal Cycler 480, Perkin Elmer Ltd) at an initial denaturation temperature of $94^{\circ} \mathrm{C}$ for five minutes. Samples were subjected to 40 cycles at $94^{\circ} \mathrm{C}, 56^{\circ} \mathrm{C}$, and $73^{\circ} \mathrm{C}$ for one minute each, followed by a final extension step at $73^{\circ} \mathrm{C}$ for 10 minutes. The PCR products were analysed by electrophoresis on a $10 \%$ polyacrylamide gel at 200 volts for $1 \frac{1 / 2}{2}$ hours. A pBR322 Hae III molecular weight marker was run simultaneously with the PCR products in a separate well to identify the PCR products of relevant size. The gel was stained with ethidium bromide and photographed under ultraviolet light.

\section{CONTAMINATION}

Strict precautions had to be taken to avoid contamination when preparing samples for PCR. The PCR mix was set up in a class II safety cabinet without the use of airflow because preliminary studies showed that increased contamination occurred when the airflow system was active. This cabinet was cleaned thoroughly before and after use with Virkon medical disinfectant (Antec International Ltd, Suffolk). The addition of template DNA into the PCR mix took place in a different laboratory on a separate bench. A set of pipettes was specifically allocated for preparation of the PCR mix, and an additional P20 pipette was used only for the addition of DNA 
Table 2 Southern blot hybridisation and PCR results showing TCR $\beta$ and TCR clonal gene rearrangements of 12 patients with LGL lymphocytosis

\begin{tabular}{|c|c|c|c|c|c|c|}
\hline \multirow{2}{*}{$\begin{array}{l}\text { Case } \\
\text { number }\end{array}$} & \multirow{2}{*}{$\begin{array}{l}\text { Southern } \\
\text { blotting with } C \beta \\
\text { probe }\end{array}$} & \multicolumn{5}{|c|}{$P C R$ of $T C R \beta$ and $T C R \gamma$ clonal gene rearrangements } \\
\hline & & $V \beta \mathcal{F 1}$ & $V \beta \mathcal{F \beta 2}$ & $D \beta 1 \mathcal{F 2}$ & $D \beta 2 f \beta 2$ & $V \gamma 101, V_{\gamma} 11, \mathcal{F} \gamma 12$ \\
\hline 01 & + & + & - & + & - & + \\
\hline 02 & + & - & + & + & + & + \\
\hline 03 & - & + & - & + & + & + \\
\hline 04 & + & + & + & + & + & - \\
\hline 05 & - & - & - & - & - & + \\
\hline 06 & - & - & - & - & - & - \\
\hline 07 & - & - & - & - & - & - \\
\hline 08 & + & - & - & + & + & + \\
\hline 09 & + & - & + & - & - & - \\
\hline 10 & - & + & + & + & + & + \\
\hline 11 & - & - & - & - & - & - \\
\hline 12 & N/A & - & - & + & + & + \\
\hline
\end{tabular}

N/A, not available due to insufficient DNA for analysis.

into the PCR mix. Pipettes were used only with disposable filter pipette tips (Anachem Ltd, Luton) to prevent contaminants entering and lodging in the barrel of the pipette, and to prevent the possibility of any contaminants from the pipette being placed into the PCR mix. Latex medical gloves were worn and changed frequently, especially after temporarily leaving the safety cabinet. Primers, dNTPs, and sterile distilled water (Antigen Pharmaceuticals, Roscrea, Ireland) were aliquoted into small volume working solutions and stored at $-20^{\circ} \mathrm{C}$. These working solutions were used once only and thrown away after the preparation of each PCR mix. All $1.5 \mathrm{ml}$ Eppendorf tubes and $0.5 \mathrm{ml}$ microtubes were autoclaved in sealed glass containers that were opened briefly within the safety cabinet during the preparation of the PCR.

\section{SENSITIVITY}

A DNA mixing experiment was performed consisting of serial dilutions of a known sample of DNA positive for TCR $\beta$ MGRs with normal DNA. The concentrations ranged from neat to $10^{-5}$ which represented a concentration of $1 \mu \mathrm{g}$ to $0.01 \mathrm{ng}$ of the clonal DNA sample. Each of the serial dilutions was amplified by PCR under the conditions described above.

\section{Results}

\section{COMPARISON BETWEEN SB HYBRIDISATION AND} PCR

Table 2 shows the results of SB hybridisation and PCR analysis of the 12 patients with persistent LGL lymphocytosis. Five cases (42\%) showed TCR $\beta$ MGRs by SB hybridisation, six cases $(50 \%)$ showed no clonal rearrangements, and one case did not produce a reliable result because of weak signals caused by insufficient DNA on the nylon membrane.

Figure 1 shows a series of positive and negative results obtained by PCR using a variety of primers for TCR $\beta$ and TCR $\gamma$ gene rearrangements. A distinct PCR band located within the specific molecular size range of 55 to 110 base pairs can be seen for each of the positive cases. The negative control samples show a diffuse smear in this region confirming a negative result. A series of high molecular weight PCR bands can also be seen in both the positive and negative DNA samples. These bands are

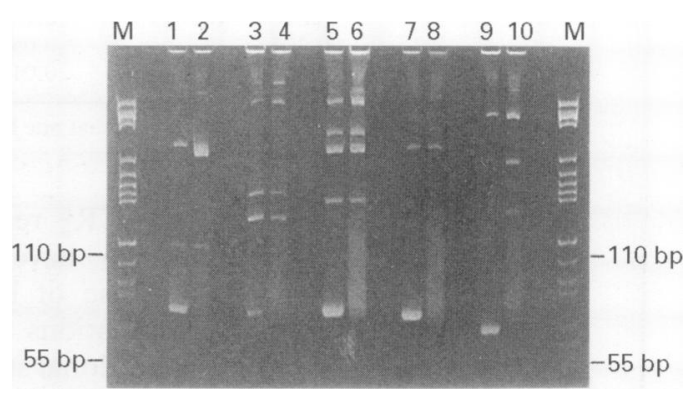

Figure 1 Polyacrylamide gel analysis of $P C R$ products detecting TCR $\beta$ and TCR $\gamma$ clonal gene rearrangements. $M$, molecular weight marker $P B R$ HaeIII. Lane 1, patient with LGL lymphocytosis (case 03) with V $\beta \exists \beta 1$ primers; Lane 2,

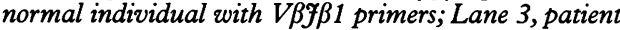
with LGL lymphocytosis (case 02) with VBf $\beta 2$ primers, Lane 4, normal individual with V $\beta \Re \beta 2$ primers; Lane 5 , patient with LGL lymphocytosis (case 02) with D $B Y \beta 1$ primers; Lane 6, normal individual with $D \beta f \beta 1$ primers; Lane 7, patient with LGL lymphocytosis (case 04) with $D \beta F \beta 2$ primers; Lane 8, normal individual with $D \beta \exists \beta 2$ primers; Lane 9, patient with LGL lymphocytosis (case 01) with Vy11,Vy101, fy 12 primers; Lane 10, normal individual with $V \gamma 11, V_{\gamma} 101, \mathcal{F} \gamma 12$ primers. Additional high molecular weight PCR bands can be seen for both normal and clonal DNA specimens. These PCR bands are non-specific and are not considered to represent clonality as they do not fall into the predicted size range for positive TCRB or TCR $\gamma$ MGRs.

non-specific and are a feature of all normal DNA samples as they do not fall within the predicted size range for positive clonal MGRs. ${ }^{14}$ The five cases shown to have TCR $\beta$ MGRs by SB hybridisation were also demonstrated by PCR using four combinations of TCR $\beta$ primers. Positive results from partial (D-J) and complete (V-J) TCR $\beta$ MGRs were indicated by a discrete band ranging in size from 55 to 100 base pairs as suggested by McCarthy et al. ${ }^{12}$ Two particular patients (cases 03 and 10) were negative by SB hybridisation but were strongly positive after PCR amplification with the partial and complete TCR $\beta$ primer combinations. An additional patient (case 12) who could not be analysed reliably by SB hybridisation due to insufficient DNA was also determined by PCR to have partial TCR $\beta$ MGRs. Thus, eight patients (67\%) were found to have TCR $\beta$ MGRs by PCR, and the remaining four cases $(33 \%)$ had no detectable TCR $\beta$ MGRs.

In addition to TCR $\beta$ gene rearrangement, seven cases (58\%) were found to have TCR $\gamma$ MGRs by PCR analysis. Positive TCR $\gamma$ MGRs were indicated by a distinct PCR band in the range of 70 to 110 base pairs. ${ }^{12}$ Combining the 
Table 3 Sensitivity assay of complete and partial TCR $\beta$ primers

\begin{tabular}{|c|c|c|c|c|}
\hline \multirow[b]{2}{*}{$\%$ clonal DNA } & \multirow{2}{*}{$\begin{array}{l}\text { Concentration of } \\
\text { leukaemic DNA in clonal } \\
\text { PB sample (ng) }\end{array}$} & \multirow[b]{2}{*}{$\begin{array}{l}\text { Total number of cells in } \\
\text { clonal PB sample }\end{array}$} & \multicolumn{2}{|c|}{ Leukaemic DNA+ normal DNA } \\
\hline & & & $\begin{array}{l}\text { Complete TCR } \\
(V \beta \mathcal{F} \beta 2)\end{array}$ & $\begin{array}{l}\text { Partial TCR } \\
(D \beta 2 f \beta 2)\end{array}$ \\
\hline 100 & 1000 & $1 \times 10^{6}$ & + & + \\
\hline 50 & 500 & $5 \times 10^{5}$ & + & + \\
\hline 40 & 400 & $4 \times 10^{5}$ & + & + \\
\hline 30 & 300 & $3 \times 10^{5}$ & + & + \\
\hline 20 & 200 & $2 \times 10^{5}$ & + & + \\
\hline 10 & 100 & $1 \times 10^{5}$ & + & + \\
\hline 5 & 50 & $5 \times 10^{4}$ & + & + \\
\hline 4 & 40 & $4 \times 10^{4}$ & + & + \\
\hline 3 & 30 & $3 \times 10^{4}$ & + & + \\
\hline 2 & 20 & $2 \times 10^{4}$ & + & + \\
\hline 1 & 10 & $1 \times 10^{4}$ & + & + \\
\hline 0.5 & 5 & $5 \times 10^{3}$ & + & + \\
\hline 0.25 & 2.5 & 2500 & - & - \\
\hline 0.125 & 1.25 & 1250 & - & - \\
\hline 0.05 & 0.5 & 500 & - & - \\
\hline 0.01 & 0.1 & 100 & - & - \\
\hline 0.005 & 0.05 & 50 & - & - \\
\hline 0.001 & 0.01 & 10 & - & - \\
\hline
\end{tabular}

* Calculated on fact that one human cell $=1$ pg genomic DNA. PB Peripheral blood.

TCR $\beta$ and TCR $\gamma$ results, nine cases $(75 \%)$ were found to have TCR $\beta$ and/or TCR $\gamma$ MGRs. The use of both TCR $\beta$ and TCR $\gamma$ primer combinations in a PCR allowed us to determine the clonal status in all 12 individuals with persistent LGL lymphocytosis.

\section{SENSITIVITY TEST}

The clonal DNA used in the sensitivity test was obtained from a patient whose $\mathrm{CD}^{+} \mathrm{T}$ lymphocytes were known to be strongly positive for TCR $\beta$ MGRs. Flow cytometry analysis of lymphocyte subsets suggested that at least $30 \%$ of the "clonal" DNA sample was of non-clonal origin $\left(\mathrm{CD}^{+}\right)$. A precise interpretation of the PCR sensitivity is therefore difficult because of the additional dilution factor caused by the presence of non-clonal DNA. In addition, the results obtained by PCR are affected by template DNA which cannot be equally efficiently amplified. The sensitivity results are consequently a conservative approximate value and may in fact be higher than that reported in this study.

Table 3 shows the sensitivity results obtained by PCR using both complete and partial TCR $\beta$ primers on serial dilutions of clonal DNA with normal DNA. A clonal PCR product was produced with the TCR $\beta$ primers when clonal DNA comprised only $0.5 \%$ of total DNA. This suggests that one clonal cell in 200 normal cells $(0.5 \%)$ may be detected by the PCR technique, a sensitivity result that at least doubles the lower $1 \%$ clonal detection limit of traditional SB analysis. ${ }^{8}$

\section{Discussion}

This study determined the clonal status of 12 individuals with persistent LGL lymphocytosis. Five cases ( $42 \%$ ) could be detected by SB analysis of the TCR $\beta$ gene rearrangements, whereas eight cases $(67 \%)$ were detected using PCR amplification. SB analysis is often difficult as it requires high quantities of DNA for restriction digestion (10-15 $\mu \mathrm{g}$ per digest) and has a low sensitivity range for the detection of clonal DNA (1-5\%). ${ }^{8}$ These factors alone may have resulted in the apparent negative results of
SB analysis of the three patients in this study who were consequently found to have TCR $\beta$ MGRs by PCR analysis. Most patients with LGL leukaemia have modest lymphocytosis despite increased numbers of circulating LGL cells. ${ }^{1}$ This feature made it difficult to obtain the high yields of DNA necessary for SB analysis. Incomplete enzymatic digestion of the DNA also resulted in extra electrophoretic bands which could not be interpreted correctly as being a monoclonal TCR $\beta$ rearrangement, a polymorphism, or a normal negative result. This phenomenon increased the risk of producing false positive results. In relation to the diagnosis of LGL leukaemia, SB analysis was impractical because the entire assay takes up to two weeks to complete, and when repeat analysis is required (providing sufficient DNA is available) it may take up to a month for a final result. Additional disadvantages include the need to use and dispose of radioactive material, and the overall high cost of the procedure.

PCR resolved many of the problems encountered with SB hybridisation. This technique requires only small quantities of DNA (approximately $50 \mathrm{pg}$ ), avoids the need for radiolabelling, and has the advantage of being extremely rapid. Sensitivity studies performed in this study suggest that one clonal cell in approximately 200 or more normal cells $(<0.5 \%)$ may be detected using the PCR technique.

The only potential disadvantage of using PCR as a diagnostic technique is that its exquisite sensitivity may lead to false positive results due to contamination of template DNA. However, this may be avoided by the use of a strict set of protocols, "PCR only" allocated equipment, and the use of negative controls for each reaction. We examined TCR $\beta$ and TCR $\gamma$ gene rearrangements by PCR as both represent the two known types of TCR, namely TCR $\alpha \beta$ and TCR $\gamma \delta$. The PCR analysis described here was initially developed by McCarthy et al to detect a majority of partial (D-J) TCR $\beta$ and complete (V-J) TCR $\gamma$ gene rearrangements as well as a proportion of complete (V-D-J) TCR $\beta$ gene rearrangements. ${ }^{12}{ }^{13}$ Eight of the 12 patients in 
the present study were positive for TCR $\beta$ MGRs by PCR, seven (58\%) for TCR $\gamma$, and nine $(75 \%)$ for at least one of the two types of TCR MGRs. Three patients (25\%) had no detectable TCR $\beta$ or TCR $\gamma$ gene rearrangements. These results suggest that the nine patients with positive TCR clonal gene rearrangements may have LGL leukaemia. However, it must be emphasised that clonality is not always equivalent to malignancy and such results must always be backed up with additional clinical information and diagnostic tests.

In conclusion, provided strict precautions are followed to prevent contamination, PCR analysis may be used as an efficient and practical alternative to SB analysis for detecting monoclonal TCR gene rearrangements when investigating the clonal nature of LGL proliferations.

This work was supported by the Haematology Research Fund of the Belfast City Hospital. The authors thank Drs ZR Desai, $C$ Bharucha and RJ Cuthbert for permission to study their patients and Dr AE Irvine for a gift of the TCR C $\beta$ probe.

1 Loughran TP. Clonal diseases of large granular lymphocytes. Blood 1993;82:1-14

2 Cooper DC, Henderson-Bakas M, Berliner N. Lymphoproliferative disorder of granular lymphocytes associated with severe neutropenia. Cancer 1993;72:1607-11.

3 Gold JE, Louis-Charles A, Ghali U, Balou A, Little SR, Athan E, et al. T-cell chronic lymphocytic leukaemia: unusual morphologic phenotypic and karyotypic features or association with light chain amyloidosis. Cancer 1991;70: 86-93.

4 Loughran TP, Kadin ME, Starkebaum G, Abkowitz JL, Clark EA, Disteche C, et al. Leukaemia of large granular lymphocytes: association with clonal chromosomal abnormalities and autoimmune neutropenia, thrombocytopenia malities and autoimmune neutropenia, thrombocytopenia
and hemolytic anaemia. Ann Intern Med 1985;102:169-75.
5 Foroni L, Foldi J, Matutes E, Catovsky D, O'Connor NJ Baer $R$, et al. $\alpha, \beta$, and $\gamma$ T-cell receptor genes: rearrangements correlate with haematological phenotyp in T-cell leukaemias. Br f Haematol 1987;67:307-18.

6 Scott CS, Richards SJ, Siva Kumaran M, Short M, Child JA, Hunt KM, et al. Transient and persistent expansions of large granular lymphocytes (LGL) and NK-associated $(\mathrm{NKa})$ cells: The Yorkshire Leukaemia Group Study. $\mathrm{Br} \mathcal{F}$ Haematol 1993:83:504-15.

7 Nash R, MacSweeny P, Zambello R, Semenzato G, Loughran TC. Clonal studies of CD3-lymphoproliferative disease of granular lymphocytes. Blood 1993;81:2363-8.

8 Van Dongen JJM, Wolvers-Tettero ILM. Analysis of immunoglobulin and T-cell receptor genes. Part II. Possibilities and limitations in the diagnosis and management of lymphoproliferative diseases and related disorders. Clinica Chimica 1991;198:93-174

9 Rambaldi A, Knowles DM, Rossini S, Bassan R, Barbui T, Dalla-Favera $R$, et al. T-cell receptor $\beta$ chain gene rearrangements in lymphoproliferative disorders of large granular lymphocytes/natural killer cells. $\mathcal{F}$ Exp Med 1985; granular lymphocytes/natural killer cells. f Exp Med 1985;

10 Papadopoulos KP, Bagg A, Bezwoda W, Mendelow BV. The routine diagnosis utility of immunoglobulin and T-cell receptor gene rearrangements in lymphoproliferative disorders. Am F Clin Pathol 1989;91:633-8.

11 Cossman J, Zehnbaurer B, Garrett CT. Gene rearrangement in the diagnosis of lymphoma/leukaemia. Guidelines for use based on a multiinstitutional study. Am 7 Clin Pathol 1991;95:347-54.

12 McCarthy KP, Sloane JP, Kabarowski JHS, Matutes E, of Wiedemann LM. The rapid detection of clonal T-cell pro- i

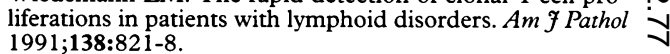

13 McCarthy KP, Sloane JP, Kabarowsk JHS, Matutes E, Wiedemann LM. A simplified method of detection of clonal rearrangements of the T-cell receptor- $\gamma$ chain gene. Diagn Mol Pathol 1992;1:173-9.

14 Slack DN, McCarthy KP, Wiedemann LM, Sloane JP. Evaluation of sensitivity, specificity, and reproducibility of an optimized method for detecting clonal rearrangements of immunoglobulin and T-cell receptor genes in formalinfixed, paraffin-embedded sections. Diagn Mol Pathol 1993; 2:223-32.

15 Foroni L, Mason P, Luzzatto L. Immunoglobulin and T-cell receptor gene analysis for the investigation of lymphoproliferative disorders. In: Catovsky $\mathrm{D}$, ed. Methods in haematol The leukaemic cell. 2nd D. Edinburgh: Churchill gy. The leukaemic cell. 2

16 Southern EM. Detection of specific sequences among DNA fragments separated by gel electrophoresis. $\mathcal{F} \mathrm{Mol}$ Biol 1975;98:503-17. 